Jurnal Informatika dan Rekayasa Perangkat Lunak (JATIKA)
Vol. 2, No. 3, September 2021, page-page. 407 413
ISSN 2723-3367
E-ISSN 2797-3492
available online at:http://jim.teknokrat.ac.id/index.php/informatika

\title{
IMPLEMENTASI GAME PERMAINAN TIMUN EMAS BERBASIS ANDROID
}

\author{
Agung Setiadi \\ Universitas Teknokrat Indonesia \\ agung_setiadi@teknokrat.ac.id
}

\begin{abstract}
Published: 30 September 2021
Abstract

This research was conducted on the basis of helping children to get to know about folklore in Indonesia. In addition, this study was conducted to help children in learning the moral values that exist in folklore. This research was conducted by creating an android-based game application with the theme of Gold Cucumber folklore. Children in Indonesia today have begun to forget the cultures that exist in their own country. One of the causes is the influx of foreign cultures that are becoming increasingly popular and starting to erode the indigenous culture of Indonesia. Therefore, the author created an androidbased folklore-themed game application so that children can be interested in one of Indonesia's existing cultures. The app was tested using the black box method and the benefits of the application were studied using questionnaire and interview methods. After the application passed in black box testing, the application was tested and received a positive response from existing questionnaires and interviews. With the results of existing research, it can be concluded that this application can carry out its duties to help children in introducing folklore culture and educating moral values well.
\end{abstract}

Keywords: Folklore, Android, Golden Cucumber, Unity, Black Box.

\begin{abstract}
Abstrak
Penelitian ini dilakukan atas dasar untuk membantu anak-anak untuk mengenal kembali tentang cerita rakyat yang ada di Indonesia. Selain itu penelitian ini dilakukan untuk membantu anak-anak dalam mempelajari nilai moral yang ada di dalam cerita rakyat. Penelitian ini dilakukan dengan cara membuat aplikasi permainan berbasis android dengan tema cerita rakyat Timun Emas. Anak-anak di Indonesia pada jaman sekarang sudah mulai melupakan budaya-budaya yang ada di negaranya sendiri. Salah satu penyebabnya adalah masuknya budaya asing yang menjadi semakin populer dan mulai menggerser budaya asli Indonesia. Oleh karena itu penulis membuat aplikasi permainan bertema cerita rakyat berbasis android agar anak-anak bisa kembali tertarik dengan salah satu budaya Indonesia yang ada. Aplikasi ini diuji menggunakan metode black box dan manfaat aplikasi tersebut diteliti menggunakan metode kuesioner dan wawancara. Setelah aplikasi lulus dalam pengujian black box, aplikasi ini diuji dan mendapat tanggapan yang positif dari kuesioner dan wawancara yang ada. Dengan hasil penelitian yang ada, dapat disimpulkan bahwa aplikasi yang dibuat ini bisa menjalankan tugasnya untuk membantu anak-anak dalam mengenalkan budaya cerita rakyat serta mendidik nilai moral dengan baik.
\end{abstract}

Kata Kunci: Cerita Rakyat, Android, Timun Emas, Unity, Black Box

To cite this article:

Agung Setiadi. (2021). IMPLEMENTASI GAME PERMAINAN TIMUN EMAS BERBASIS ANDROID. Jurnal Informatika dan Rekayasa Perangkat Lunak, Vol(2) No(3), 407-413.

\section{PENDAHULUAN}

Cerita rakyat merupakan salah satu budaya yang dimiliki oleh bangsa Indonesia. Tiap suku bangsa di Indonesia memiliki cerita rakyat yang menguandung nilai-nilai moral yang dapat disimak untuk pendidikan karakter. Semua masyarakat menggunakan cerita untuk menyampaikan nilai kelompok (Arpiansah et al., 2021). Dengan cerita yang menghibur, moral yang terkandung didalamnya dapat disampaikan dengan mudah. Cerita juga membantu memperluas kesadaran budaya lain. Selain itu cerita bisa digunakan untuk tujuan pendidikan. Cerita 
juga dapat membantu mengembangkan kepekaan sastra anak, dan mendengarkan cerita mengesankan struktur cerita dalam pikiran anak-anak (Pratama \& Surahman, 2020; Sintaro, 2020). Cerita membantu dalam mempelajari kosakata, dan anak-anak yang mampu bercerita sering memperoleh kemampuan verbal yang tinggi dan meningkatkan rasa percaya diri.

Namun, dengan globalisasi yang telah terjadi di Indonesia, keduayaan Indonesia mulai tergeser dengan kebudayaan-kebudayaan asing yang terus masuk ke Indonesia. Datangnya pengaruh barat di anggap sebagai ciri khas kemajuan dalam ekspresi kebudayaan kekinian yang belum tentu sesuai dengan kebutuhan situasi dan kondisi masyarakat sendiri. Keadaan tesebut terus mengikis budaya dan kearifan lokal yang menjadi warisan kebudayaan masyarakat nusantara. Dari sinilah juga nilai tradisional secara perlahan mengalami kepunahan karena tidak mampu bersaing dengan budaya moden dalam bentuk pergaulan masyarakat.

Permasalahan yang dihadapi bangsa Indonesia di era globalisasi sekarang ini sudah mengarah pada krisis multidimensi. Multidimensi yang berarti permasalahan yang terjadi tidak saja menyentuh aspek fisik semata, akan tetapi juga berkaitan dengan perubahan non fisik, yaitu pergeseran budaya, kebiasaan, dan tata perilaku sosial masyarakat. Menjamurnya budaya dan kebiasaan-kebiasaan orang barat yang berlawanan dengan kebudayaan bangsa dapat mengakulturasi bahkan menggeser kebudayaan lokal. Walaupun begitu, era globalisasi juga membawa perkembangan positif bagi Indonesia, salah satunya adalah teknologi untuk Indonesia. Salah satu contoh perkembangan teknologi yang terjadi di Indonesia adalah perkembangan dalam bagian tenologi informasi dan komunikasi, seperti telepon genggam, komputer, internet, dan lain-lainnya (Alita et al., 2020; Ichsan et al., 2020; Najib et al., 2020).

Dalam telepon genggam, perkembangan teknologinya sudah bisa dilihat dengan jelas. Sebelumnya, telepon genggam mempunyai model yang sederhana, serta hanya mempunyai dua fungsi utama, yaitu telepon dan SMS. Selain itu desain dan permainan yang dimiliki juga sederhana. Namun, telepon genggam saat ini sudah mempunyai fungsi yang lebih banyak, seperti foto, merekam, dan menggunakan internet. Warna yang dapat digunakan oleh telepon genggam saat ini juga banyak. Model telepon genggam yang dibuat juga sudah berubah, dengan bentuk yang lebih tipis dan touchscreen. Dengan fungsi telepon genggam yang berkembang bersama jaman, masyarakat mulai menyadari kepentingan telepon genggam dan mulai membelinya. Berdasarkan survei yang dilakukan oleh tim APJII (APJII, 2016), terdapat 92,8 juta dari 256,2 juta masyarakat Indonesia yang telah menggunakan internet melalui telepon genggamnya. Dari masyarakat tersebut, generasi muda pun ikut termasauk dalam pengguna telepon genggam.

Bermain game merupakan salah satu aktivitas hiburan yang dilakukan manusia untuk menghilangkan kejenuhan di sela aktivitas harian yang terus berulang (Ahdan et al., 2020; Listiono et al., 2021; Rahmanto \& Utama, 2018). Bermain tidak hanya berfungsi untuk hiburan, bermain juga memiliki fungsi untuk melatih kemampuan berpikir yang dapat mengasah otak manusia (Borman \& Putra, 2018; Putra et al., 2016; Saputra et al., 2020). Memainkan game edukasi, seorang anak secara langsung belajar membaca untuk memainkan sebuah game. Selain itu, dalam memainkan sebuah game, otak bekerja lebih keras untuk berstrategi dalam memecahkan masalah dalam sebuah permainan. Stimulasi otak ini perperan juga dalam melatih kemampuan motorik anak.

\section{METODE PENELITIAN \\ Teknik Pengumpulan Data}

Adapun teknik yang digunakan untuk mengumpulkan data adalah sebagai berikut:

a. Pengamatan

Pengamatan adalah metode pengumpulan data dengan cara mengadakan tinjauan secara langsung ke objek yang diteliti. Untuk mendapatkan data yang sesuai dan meyakinkan maka penulis melakukan pengamatan langsung terhadap beberapa peramainan lain yang memiliki tema yang sama (Sulistiani et al., 2020).

b. Studi Pustaka

Studi pustaka dilakukan untuk mendapatkan data-data yang dibutuhkan penulis dalam melakukan penelitian. Penulis melakukan pengumpulan data dengan cara membaca dan mempelajari bukubuku, situs web, makalah ataupun referensi lain yang berhubungan dengan masalah yang dibahas (Setiawansyah et al., 2021).

c. Kuesioner

Kuesioner digunakan untuk mengumpulkan data-data penilaian aplikasi yang akan dihitung untuk mengetahui keberhasilan aplikasi dalam menjalankan misinya. Kuesioner akan diberikan kepada anak-anak setelah mereka memainkan aplikasi yang dibuat (Sulistiani et al., 2021). 
d. Wawancara

Wawancara digunakan untuk mengumpulkan data-data penilaian aplikasi berhubungan dengan pendidikan dari padangan orang yang mengetahui prilaku anak-anak (Very \& Pasha, 2021; Yana et al., 2020).

\section{Konsep Permainan}

Konsep dari permainan yang dibuat adalah permainan 2D platformer yang menggunakan tema cerita rakyat Timun Emas. Diagram use case yang ada pada aplikasi permainan ini hanya memiliki satu aktor, yaitu pengguna. Pada gambar 1 menunjukan apa yang bisa dilakukan pengguna pada aplikasi permainan ini (Anita et al., 2020; Nurmanto \& Gunawan, 2020; Pasaribu et al., 2019).

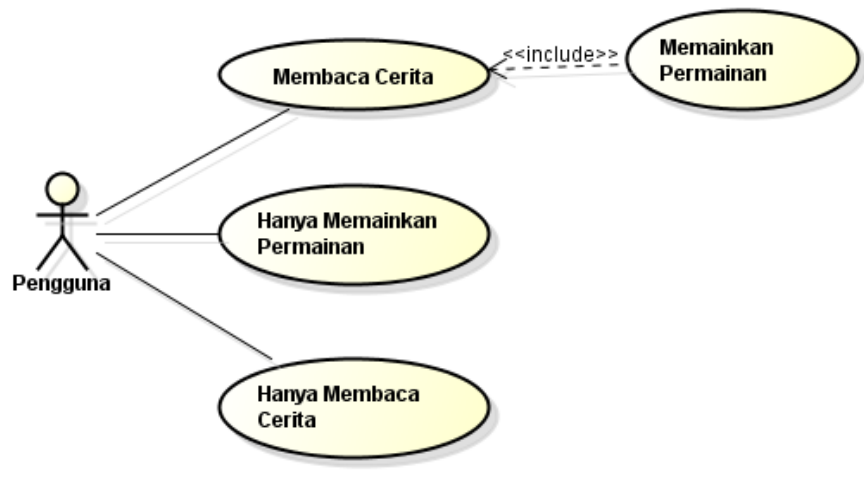

Gambar 1. Use Case Pengguna

Berdasarkan gambar diatas, penulis membuat konsep dari permainan yang akan dibuat seperti pada gambar 2 .

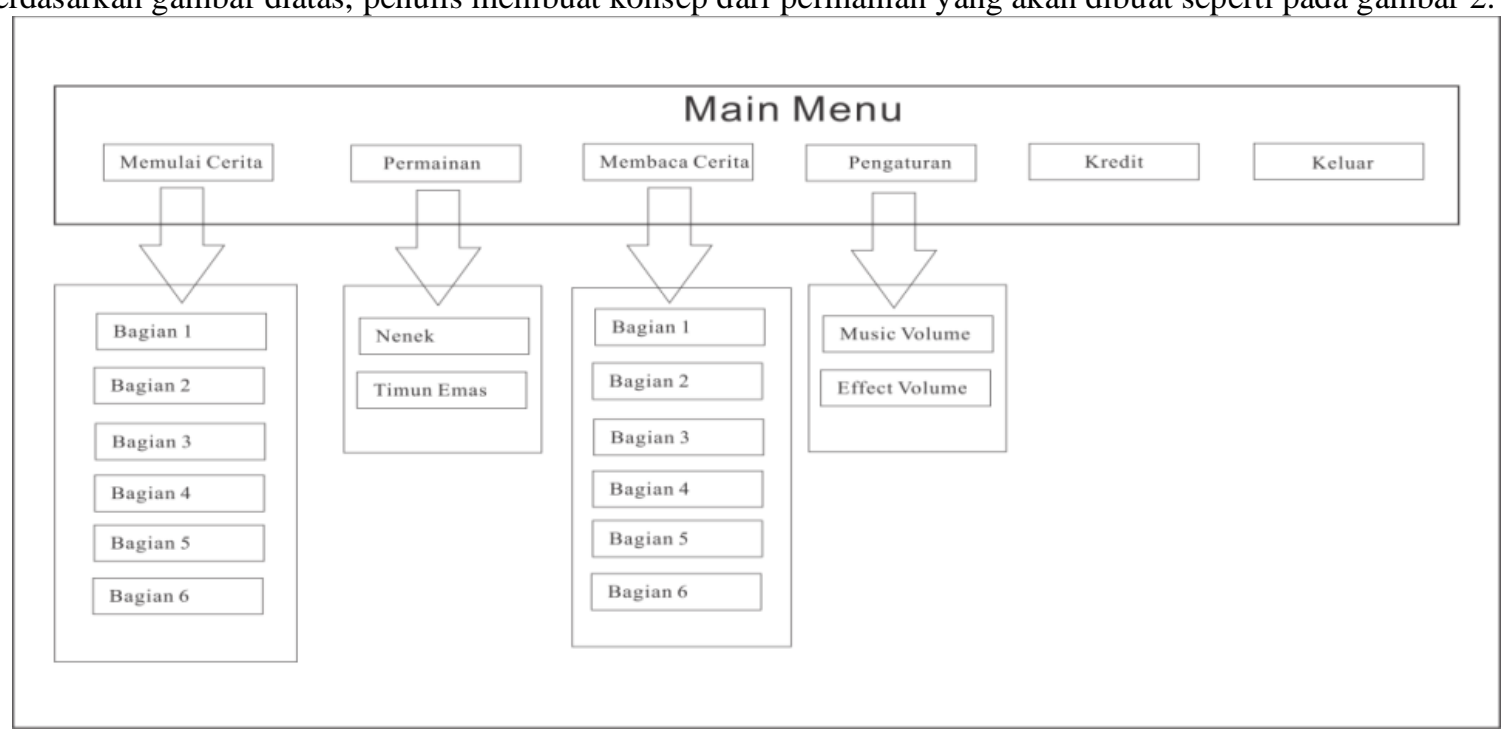

Gambar 2. Konsep Permainan

Dalam gambar tersebut, terdapat enam pilihan pada menu utama. Pilihan keluar untuk keluar dari permainan, pilihan kredit untuk melihat siapa saja yang terlibat dalam pembuatan permainan, pilihan option untuk mengatur musik dan suara permainan, pilihan membaca cerita untuk pemain membaca cerita tanpa diselangi permainan, pilihan permainan untuk memulai permainan tanpa adanya cerita, dan memulai cerita untuk memulai cerita yang diselingi unsur pemainan.

Dari pilihan memulai cerita dan membaca cerita akan terbuka enam pilihan lain. Dari bagian satu yang mencirtakan tentang bagaimana nenek menemukan timun emas sampai dengan bagian enam yang menceritakan bagaimana Timun Emas bisa mengalahkan Buto Ijo. Selain itu dalam pilihan permainan pemain bisa memilih 
karakter yang ingin dimainkan, antara nenek dan Timun Emas. Dengan memainkan Timun Emas, permainan akan menjadi lebih sulit daripada memainkan nenek karena kecepatan permainan yang ditambahkan.

\section{HASIL DAN PEMBAHASAN}

\section{Tampilan Menu Utama}

Dibawah ini merupakan hasil screenshot menu utama setelah menjalankan aplikasi Timun Emas di android

Tabel 1. Tampilan Menu Utama

Splash

\section{Tampilan Menu Permainan}

Dibawah ini merupakan hasil screenshot menu permainan setelah menjalankan aplikasi Timun Emas di android 
Tabel 2. Tampilan Menu Permainan

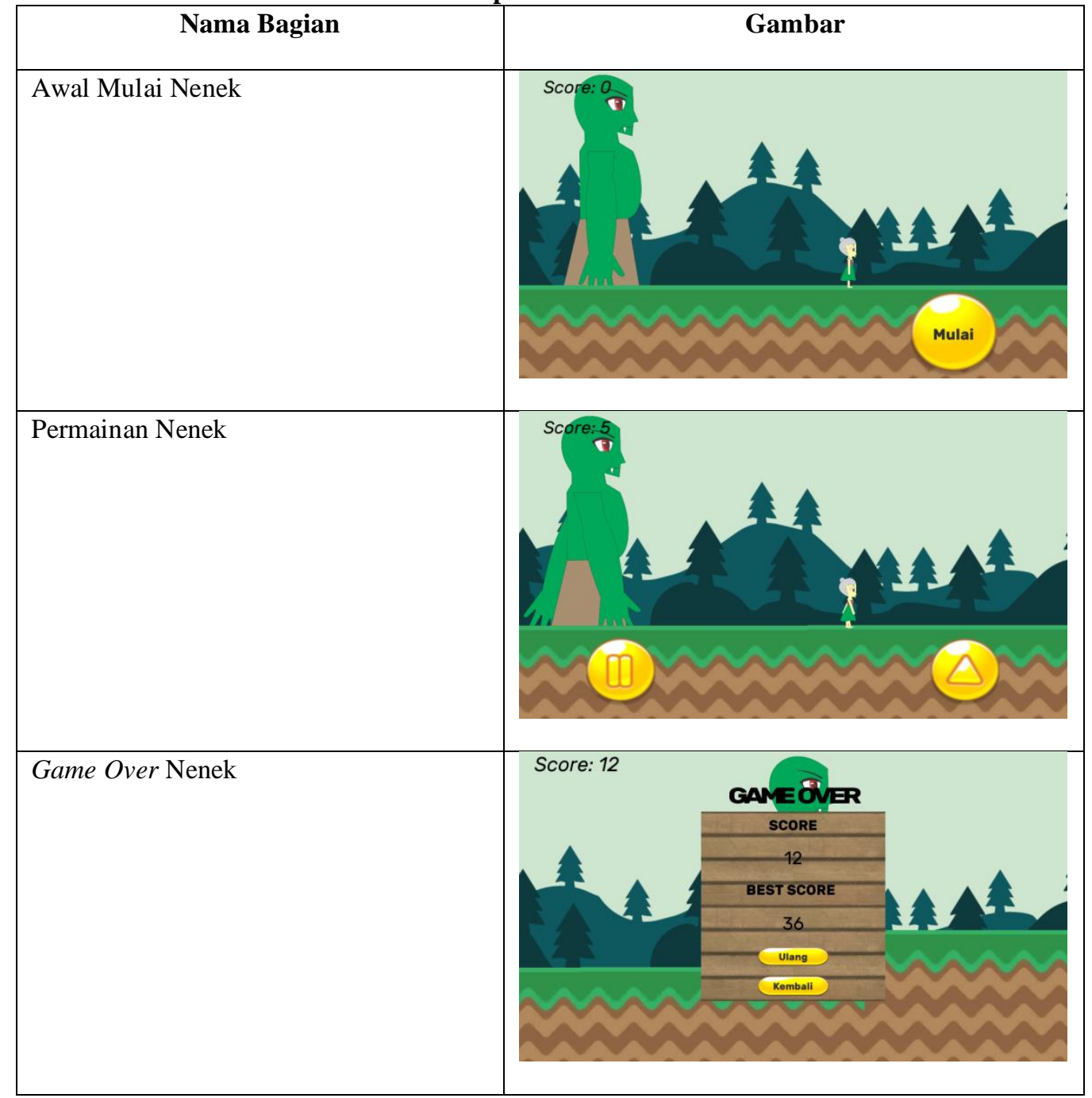

\section{Tampilan Menu Cerita}

Dibawah ini merupakan hasil screenshot menu cerita setelah menjalankan aplikasi Timun Emas di android

Tabel 3. Tampilan Menu Cerita

\begin{tabular}{|l|l|l|l|l|}
\hline \multicolumn{2}{|c|}{ Nama Bagian } & Gambar \\
\hline Awal Cerita & & \\
\hline
\end{tabular}




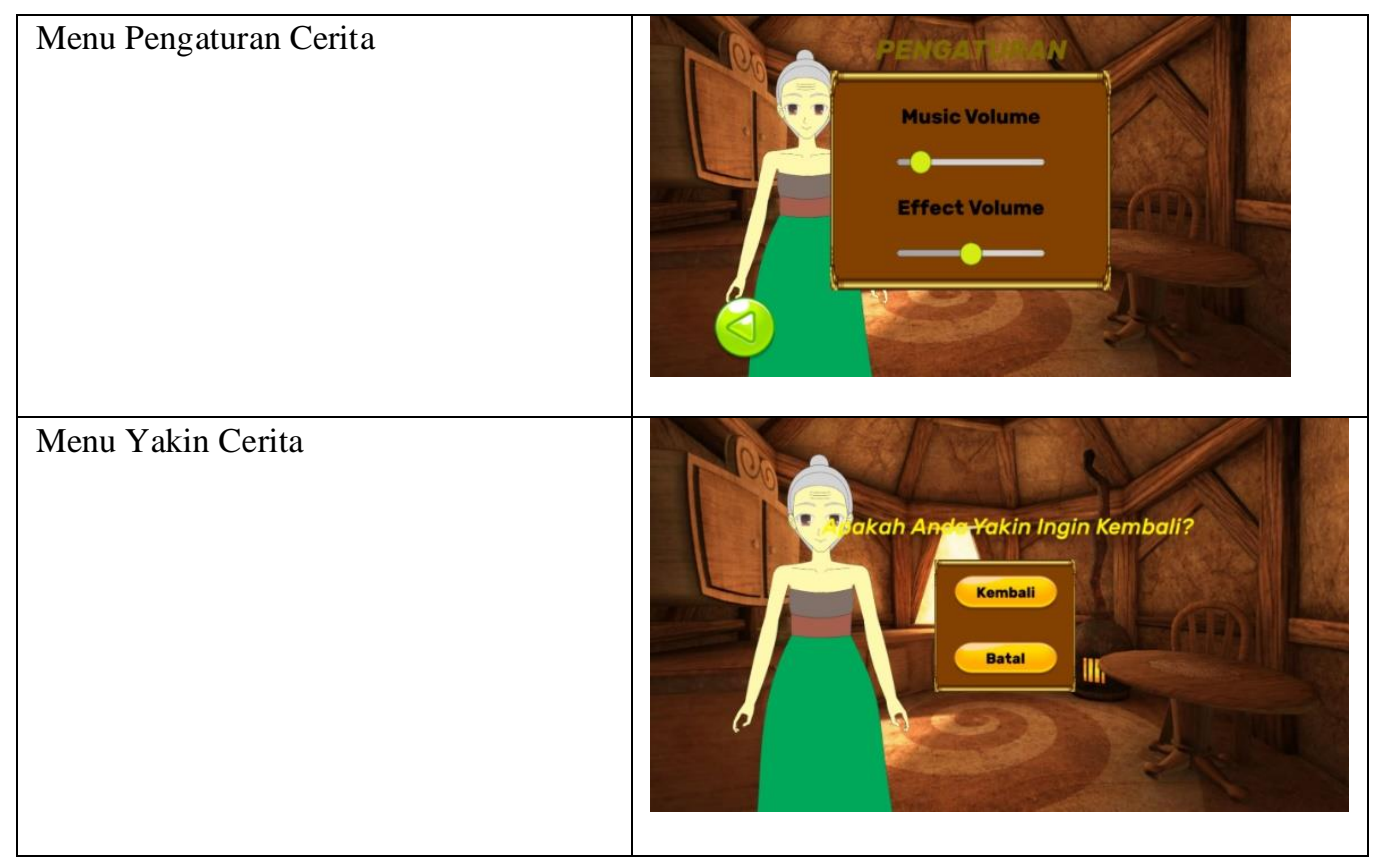

\section{Hasil Pengujian Kuesioner}

Penulis melakukan penelitian kuesioner di salah satu kelas di SD Insan Mandiri Bandarlampung dengan jumlah responden sebanyak 26 anak. Terdapat sembilan pertanyaan yang diberikan kepada anak-anak, yaitu.

a. Aplikasi mudah digunakan

b. Gambar terlihat menarik

c. Tulisan mudah dibaca

d. Cerita yang disampaikan mudah dimengerti

e. Mengetahui cara main dengan cepat

f. Aplikasi ini dapat mendidik bahasa pemain

g. Aplikasi ini dapat mendidik moral pemain

h. Senang memainkan aplikasi ini

i. Aplikasi ini membuat tertarik untuk membaca cerita rakyat yang lain

\section{SIMPULAN}

Dari hasil penelitian yang didapat, dapat disimpulkan bahwa aplikasi permainan Timun Emas berbasis android yang dibuat menggunakan unity dapat berjalan dengan baik. Dari hasil kuesioner yang didapat dari salah satu kelas di SD Insan Mandiri dengan jumlah dua puluh enam anak, dapat disimpulakan bahwa aplikasi permainan Timun Emas yang dibuat telah berhasil menjalankan tugasnya untuk membuat anak-anak tertarik dengan cerita rakyat yang lain. Selain itu anak-anak juga setuju jika aplikasi tersebut membantu mereka dalam mendidik nilai bahasa dan juga moral. Dari hasil wawancara yang didapat juga dapat disimpulkan bahwa aplikasi permainan timun emas dapat digunakan sebagai media dalam membantu pemain dalam mendidik nilai moral yang ada dalam cerita rakyat.

\section{REFERENSI/DAFTAR PUSTAKA}

Ahdan, S., Priandika, A. T., Andhika, F., \& Amalia, F. S. (2020). PERANCANGAN MEDIA PEMBELAJARAN TEKNIK DASAR BOLA VOLI MENGUNAKAN TEKNOLOGI AUGMENTED REALITY BERBASIS ANDROID LEARNING MEDIA FOR BASIC TECHNIQUES OF VOLLEYBALL USING ANDROID-BASED AUGMENTED REALITY TECHNOLOGY.

Alita, D., Tubagus, I., Rahmanto, Y., Styawati, S., \& Nurkholis, A. (2020). Sistem Informasi Geografis Pemetaan Wilayah Kelayakan Tanam Tanaman Jagung Dan Singkong Pada Kabupaten Lampung Selatan. Journal of Social Sciences and 
Technology for Community Service (JSSTCS), 1(2).

Anita, K., Wahyudi, A. D., \& Susanto, E. R. (2020). Aplikasi Lowongan Pekerjaan Berbasis Web Pada Smk Cahaya Kartika. Jurnal Teknologi Dan Sistem Informasi, 1(1), 75-80.

Arpiansah, R., Fernando, Y., \& Fakhrurozi, J. (2021). GAME EDUKASI VR PENGENALAN DAN PENCEGAHAN VIRUS COVID-19 MENGGUNAKAN METODE MDLC UNTUK ANAK USIA DINI. Jurnal Teknologi Dan Sistem Informasi, 2(2), 88-93.

Borman, R. I., \& Putra, A. S. (2018). Game Pengenalan Huruf Hijaiyah Untuk Anak Autis Dengan Penerpan Pendekatan Edukasi Multisensori. SEMNASTEKNOMEDIA ONLINE, 6(1), 1-6.

Ichsan, A., Najib, M., \& Ulum, F. (2020). Sistem Informasi Geografis Toko Distro Berdasarkan Rating Kota Bandar Lampung Berbasis Web. Jurnal Teknologi Dan Sistem Informasi, 1(2), 71-79.

Listiono, E. D., Surahman, A., \& Sintaro, S. (2021). ENSIKLOPEDIA ISTILAH GEOGRAFI MENGGUNAKAN METODE SEQUENTIAL SEARCH BERBASIS ANDROID STUDI KASUS: SMA TELADAN WAY JEPARA LAMPUNG TIMUR. Jurnal Teknologi Dan Sistem Informasi, 2(1), 35-42.

Najib, M., Satria, D., Saputra, F., Pasha, D., Informasi, S., Indonesia, U. T., Indonesia, U. T., Android, S., Uno, A., \& Arduino, A. (2020). MIT APP INVERTOR PADA APLIKASI SCORE BOARD UNTUK PERTANDINGAN OLAHRAGA BERBASIS ANDROID. Tekno Kompak, 14(2), 115-120.

Nurmanto, D., \& Gunawan, R. D. (2020). PEMANFAATAN AUGMENTED REALITY DALAM APLIKASI MAGIC BOOK PENGENALAN PROFESI UNTUK PENDIDIKAN ANAK USIA DINI. 1(1), 36-42.

Pasaribu, A. F. O., Darwis, D., Irawan, A., \& Surahman, A. (2019). Sistem Informasi Geografis untuk Pencarian Lokasi Bengkel Mobil di Wilayah Kota Bandar Lampung. Jurnal Tekno Kompak, 13(2), 1-6.

Pratama, R. R., \& Surahman, A. (2020). PERANCANGAN APLIKASI GAME FIGHTING 2 DIMENSI DENGAN TEMA KARAKTER NUSANTARA BERBASIS ANDROID MENGGUNAKAN CONSTRUCT 2. Jurnal Informatika Dan Rekayasa Perangkat Lunak, 1(2), 234-244.

Putra, D. W., Nugroho, A. P., \& Puspitarini, E. W. (2016). Game Edukasi berbasis android sebagai media pembelajaran untuk anak usia dini. JIMP-Jurnal Informatika Merdeka Pasuruan, 1(1).

Rahmanto, Y., \& Utama, R. Y. (2018). Penerapan Teknologi Web3D Berbasis Android Sebagai Media Pembelajaran Gerakan Dasar Silat. Jurnal TAM (Technology Acceptance Model), 9(1), 7-14. http://ojs.stmikpringsewu.ac.id/index.php/JurnalTam/article/view/593

Saputra, V. H., Darwis, D., \& Febrianto, E. (2020). Rancang bangun aplikasi game matematika untuk penyandang tunagrahita berbasis mobile. Jurnal Komputer Dan Informatika, 15(1), 171-181.

Setiawansyah, S., Adrian, Q. J., \& Devija, R. N. (2021). Penerapan Sistem Informasi Administrasi Perpustakaan Menggunakan Model Desain User Experience. Jurnal Manajemen Informatika (JAMIKA), 11(1), 24-36.

Sintaro, S. (2020). RANCANG BANGUN GAME EDUKASI TEMPAT BERSEJARAH DI INDONESIA. Jurnal Informatika Dan Rekayasa Perangkat Lunak, 1(1), 51-57.

Sulistiani, H., Setiawansyah, S., \& Darwis, D. (2020). Penerapan Metode Agile untuk Pengembangan Online Analytical Processing (OLAP) pada Data Penjualan (Studi Kasus: CV Adilia Lestari). Jurnal CoreIT: Jurnal Hasil Penelitian Ilmu Komputer Dan Teknologi Informasi, 6(1), 50-56.

Sulistiani, H., Yuliani, A., \& Hamidy, F. (2021). Perancangan Sistem Informasi Akuntansi Upah Lembur Karyawan Menggunakan Extreme Programming. Technomedia Journal, 6(01 Agustus).

Very, V. H. S., \& Pasha, D. (2021). Komik Berbasis Scientific Sebagai Media Pembelajaran di Masa Pandemik Covid-19. SJME (Supremum Journal of Mathematics Education), 5(1).

Yana, S., Gunawan, R. D., \& Budiman, A. (2020). SISTEM INFORMASI PELAYANAN DISTRIBUSI KEUANGAN DESA UNTUK PEMBANGUNAN (STUDY KASUS: DUSUN SRIKAYA). Jurnal Informatika Dan Rekayasa Perangkat Lunak, 1(2), 254-263. 